\title{
AVALIAÇÃO NEUROLÓGICA E DO LfQUIDO CEFALORRAQUEANO EM CRIANÇAS COM MENINGITE MENINGOCÓCICA DO SOROGRUPO A
}

\author{
A. U. BRESOLIN *
}

Entre as infecções que acometem a criança, as que se assestam no sistema nervoso são as de maior gravidade. O prognóstico das meningites, dentre vários outros fatores, guarda intima relação com o agente etiológico e a faixa etária. As alterações neurológicas apresentadas pelos pacientes com meningites bacterianas foram e continuam sendo motivo de publicações, as quais, inquestionavelmente, concorrem para uma mais profunda compreensão de tais anormalidades, proporcionando, conseqüentemente, um melhor manuseio delas. De uma maneira geral, os trabalhos que se referem às anormalidades neurológicas decorrentes das meningites meningocócicas não estabelecem clara comparação entre os diversos sorogrupos de meningococos. Em nosso meio, apenas o trabalho de Lefèvre \& col. ${ }^{27}$ aborda, especificamente, as repercussões neurológicas oriundas da meningite meningocócica em crianças, embora esta doença ainda campeie entre nós, sendo oportuno lembrar que, ainda há pouco, grassava sob a forma de uma enorme epidemia. Mais difícil, ainda, é o conhecimento das repercussões para cada sorotipo de meningococo.

Outro aspecto que merece ser ventilado diz respeito aos critérios utilizados na avaliação do resultado do exame citológico e químico do líquido cefalorraqueano (LCR) por ocasião da alta hospitalar dos pacientes tratados de meningite. A falta de maiores conhecimentos na avaliação dos dados do LCR por ocasião da alta, nos casos de meningite, deixa o médico inseguro quanto ao momento em que deve considerar o paciente curado. As vezes, o tratamento prolonga-se por tempo desnecessário, criando situações angustiantes provocadas por punções repetidas até que o médico, para sua segurança, obtenha um exame de LCR normal ou que se encaixe num dos critérios estabelecidos por alguns autores $47,52,53,54$.

A experiência que adquirimos como neuropediatra, num hospital de moléstias infecciosas como é o "Emilio Ribas", motivou-nos e proporcionou possibilidades para execução deste trabalho. Nosso objetivo, na presente publicação, é apresentar os resultados obtidos em 255 casos de meningite determinada pelo meningococo do sorogrupo A, em crianças de diversas faixas etárias, tra-

Resumo da Dissertaçăo para Mestrado, Área de Neurologia do Curso de Pós Graduaçáo da Faculdade de Medicina da Universidade de săo Paulo: * Médico Chefe da Seçăo de Diagnóstico e Terapêtica do Serviço de Neurologia do Hospital do Servidor Público de Săo Paulo e Neuropediatra do Hospital Fmillo Ribas. 
tados com ampicilina. Os casos serão analisados e discutidos em confronto com os dados da literatura compulsada quanto às alterações neurológicas constatadas durante o período de internação, bem como os dados do exame citológico e químico do LCR por ocasião da alta hospitalar.

\section{MATERIAL E MÉTODOS}

O material é constituído de 255 crianças com o diagnóstico de meningite meningicócica do sorogrupo A, como doença primária, internadas no periodo de 1976 a 1977, nass enfermarias do Hospital Emilio Ribas. Este grupo de 255 pacientes é constituído por crianças na faixa etária de zero a 12 anos, cabendo ressaltar que a maioria dós pacientes tinha menos de cinco anos de idade. Os pacientes mais jovens eram quatro crianças de dois meses de idade, e, no limite extremo de idade, isto é com 12 anos, havia três pacientes. Com o objetivo de estudar os sinais e sintomas clínicos, bem como as anormalidades neurológicas nas diversas faixas etárias, a exemplo de Seshia \& col. 44, dividimos em quatro grupos os nossos pacientes. No Grupo I (menores de 13 meses) havia $49(19,22 \%)$, no Grupo II (entre. 13 e 36 meses) havia 78 (30,59\%), no Grupo III (entre 37 e 72 meses) havia $62(24,31 \%)$ e no Grupo IV (maiores de 72 meses) havia $66(25,88 \%)$ pacientes.

Objetivando uma conduta padronizada na avaliação neurológica destes pacientes, seguimos a metodologia sistematizada, em nosso meio, por Lefèvre 26 e Diament 13. O exame químico e citológico do LCR foi efetuado no laboratório do Hospital Emilio Ribas, enquanto que a identificação do agente etiológico, mediante cultura e/ou imunoeletroforese cruzada foi feita no Instituto Adolfo Lutz. As amostras do LCR, utilizadas para efeito deste trabalho, foram aquelas colhidas por ocasião da internação e da alta hospitalar.

Os pacientes foram submetidos a antibioticoterapia com ampicilina na dose de 200 a $400 \mathrm{mg} / \mathrm{Kg} /$ dia, por via endovenosa, dividida em quatro doses diárias, conforme orientação estabelecida pela chefia clínica deste hospital. No tratamento do edema cerebral, foram utilizadas a dexametasona e o manitol, nas doses definidas por Smith \& col. 47. Seguimos também o mesmo esquema estabelecido por estes autores 47 no tratamento das crises convulsivas, com exceção do emprego da fenil-etil-malonil-uréia por via endovenosa.

\section{RESULTADOS}

Os nossos resultados serão expostos, observados os diversos grupos etários, em duas partes. Na primeira, são apresentados os dados da fase aguda: a) aspectos clínicos antes da internação; b) intercorrências neurológicas após a admissão hospitalar; c) aspectos citológicos e químicos do LCR; d) taxa de mortalidade. Na segunda, são analisadas as anormalidades neurológicas e os dados citológicos e químicos do LCR, por ocasião da alta hospitalar.

1.1 Aspectos Clínicos Gerais por Ocasião da Admissão Hospitalar - Nos pacientes desta casuística podemos observar que, no Grupo I, o binômio alteração do estado de consciência (AEC) e febre estava presente em todos (100\%); no Grupo II, em 77 
$(98,72 \%)$; no Grupo III, em $60(96,77 \%)$; e, no Grupo IV, em $62(93,94 \%)$, sendo certo, contudo, que neste último grupo houve um ligeiro predomínio para o binômio AEC e sinais de irritação meníngea (SIM), presente em 65 pacientes $(98,48 \%)$ ). A seguir, a associação de dados clínicos mais frequientemente presente nestes grupos, foi a tríade AEC, febre e SIM, com exceção do Grupo I, no qual a tríade AEC, febre e fontanela tensa ou abaulada foi ligeiramente superior. A primeira triade foi constatada em 61 pacientes (92,42\%) do Grupo IV, em 57 (91,94\%) do Grupo III, em 69 (88,46\%) do Grupo II e em $29(59,18 \%)$ do Grupo I. A última tríade foi constatada em 31 pacientes $(63,27 \%)$ do Grupo I.

1.2 Intercorrencias Neurológicas Após a Admissão Hospitalar - Dos 255 pacientes estudados, 27 (10,59\%) apresentaram intercorrências neurológicas. Verificamos que anormalidades neurológicas ocorreram em 11 pacientes (22,45\%) do Grupo I, em 7 (8,97\%) do Grupo II, em $3(4,84 \%)$ do Grupo III e em 6 (9,09\%) do Grupo IV. A manifestação epiléptica (ME) foi a intercorrência neurológica mais freqüentemente constatada nos quatro grupos, porém, com nítido predomínio no Grupo I. A ataxia e a surdez associadas verificaram-se apenas entre os pacientes do Grupo III e IV; a ataxia isolada foi observada somente no Grupo II, enquanto que a surdez foi observada apenas entre os pacientes dos Grupos III e IV. A involução neuropsicomotora (INPM) e a coleção subdural (CS) foram notadas tão só entre os pacientes do Grupo I. Déficits motores (DM) não foram observados entre os pacientes do Grupo III.

1.3 Aspectos do Liquido Cefalorraqueano por Ocasião da Admissão Hospitalar - Os dados citológicos e químicos do LCR revelaram que 67,37\% dos casos apresentavam células em número superior a $1000 / \mathrm{mm} 3$, neutrófilos em porcentagem acima de $70 \%$, proteínas em taxa superior a $100 \mathrm{mg} \%$ e glicose em taxa inferior a $10 \mathrm{mg} \%$. Por outro lado, num outro extremo, havia três pacientes com exame citológico e químico compatível à denominada meningite asséptica, um caso no qual a anormalidade era a presença de 5 células/mm3, e outro com exame citológico e químico normal.

1.4 Mortalidade - O 6́bito foi constatado em 11 pacientes $(4,31 \%)$ dos 255 desta casuistica.

2.1 Anormalidades Neurologicas por Ocasião da Alta Hospitalar - Por ocasião da alta hospitalar constatamos que 14 pacientes $(5,49 \%)$ apresentavam anormalidades neurológicas.

2.2 Aspecto do Liquido Cefalorraqueano por Ocasião da Alta Hospitalar - Por ocasião da interrupção da medicação antimicrobiana podemos observar que o exame citológico e químico do LCR revelavam os seguintes resultados. O número de células/mm3 variou de: um a quatro em 15,23\%, de 5 a 30 em $50,33 \%$, de 31 a 50 em 17,88\%, de 51 a $100 \mathrm{em} 11,92 \%$ e de 116 a 153 em 4,64\% dos pacientes. As porcentagens de neutrófilos foram de zero em 54,97\%, de um a cinco em 33,77\%, de 6 a 10 em $5,96 \%$, de 11 a 19 em 1,33\%, de 20 a 29 em 0,66\%, de 30 a 39 em 2,65\% e de 57 em

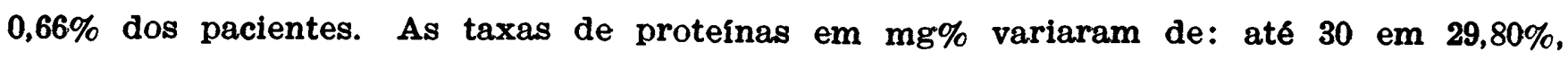

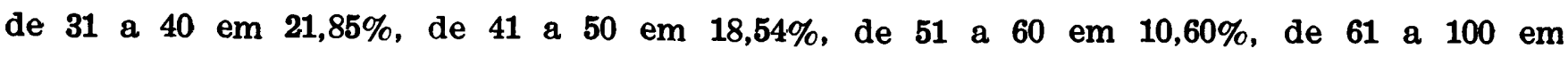
$14,57 \%$ e de 106 a 150 em 4,64\% dos pacientes. A taxa de glicose em mg\% foi igual

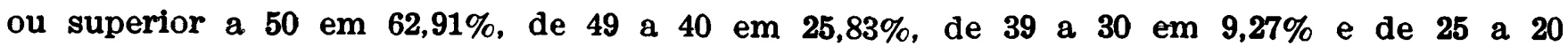
em $1,99 \%$ dos pacientes. 


\section{COMENTARIOS}

$\mathrm{O}$ exato mecanismo pelo qual o meningococo acomete as meninges partindo da nasofaringe, não está ainda completamente esclarecido 2,41. Em geral admite-se que a doença meningocócica resulta da disseminação hemática desse organismo a partir da nasofaringe. Meningite ou meningoccocemia, todavia, é complicação pouco comum da colonização da nasofaringe por esta bactéria $\mathbf{6 , 5 2}$. Banks e McCartney ${ }^{4}$ sugerem que o meningococo inicialmente acomete os vasos cerebrais ou meníngeos e, então, alcança o espaço subaracnóideo. Segundo Einhorn ${ }^{16}$, há razões para se acreditar que a lesão endotelial dos vasos cerebrais precede a meningite pelo meningococo ou $H$. influenzae, e que o grau de lesão vascular vai determinar se o paciente apresentará sintomatologia de encefalite, além da de meningite. A menningite meningocócica freqüentemente é uma meningencefalite. Numa fase precoce, o componente encefalítico pode resultar dos efeitos da endotoxina sobre os centros vitais profundos; mais tardiamente, decorrerá, das extensas vasculites cerebrais. A pia-máter pode ser francamente hemorrágica e as vasculites podem determinar múltiplos enfartes cerebrais ${ }^{52}$. O comprometimento das estruturas do sistema nervoso, nas meningites bacterianas agudas, tem sido bem documentado por vários autores $1,2,4,7,15,38,39,47,55$.

A análise global de nossos resultados caracteriza perfeitamente a existência não só de comprometimento meningeo, como também do parênquima cerebral. Embora a análise dos aspectos clínicos e laboratoriais apresentam limitações, consideramos válidas as informações obtidas neste trabalho.

\section{Aspectos Clínicos Gerais por Ocasião da Admissão Hospitalar.}

1.1 Alteração do Estado de Consciência (AEC) - Todos os pacientes desta. casuística apresentavam AEC, por ocasião da admissão hospitalar. Tal constatação clínica, sabidamente presente na grande maioria dos pacientes, não pode ser considerada condição "sine qua non" para que o diagnóstico de meningite bacteriana aguda seja lembrado, pois a ausência dessa anormalidade, embora não constatada entre nossos pacientes, tem sido observada por alguns autores 11,27. Dentre as várias formas de AEC, a prostração foi a mais freqüente nos quatro grupos estudados, seguida de irritabilidade nos pacientes do Grupo 1 e estupor nos demais grupos.

1.2 Hipertermia - Este sinal tem freqüência destacada no quadro clínico da meningite meningocócica. No entanto a febre não tem, necessariamente, presença obrigatória no quadro. clínico da moléstia. Esse sinal que denota, na maioria das vezes a presença de infecção, estava ausente em 7 (2,75\%) de nossos pacientes, por ocasião da internação hospitalar. A ausência de febre, em pacientes com meningite meningocócica, também tem sido observada na casuística de outros autores 11,24,27,43.

1.3 Sinais de Irritação Meningea (SIM) - Tais sinais foram estudados de modo global. Não avaliamos a incidência de cada sinal meníngeo em particular; entretanto, constatamos que nossos pacientes podiam apresentar um, dois 
ou mais sinais meningeos, na dependência da idade e do diagnóstico mais ou menos precoce. Notamos a presença de SIM em 223 (87,45\%) dos 255 pacientes estudados. Seibel ${ }^{43}$ menciona achado muito próximo desse, em crianças com meningite meningocócica. Nos quatro grupos etários estudados, observamos SIM em 59,18\% dos pacientes do Grupo I, em 89,74\% do Grupo II, em $95,16 \%$ do Grupo III e em $98,48 \%$ do Grupo IV. Incidência próxima daquela por nós constatada, em pacientes menores de 13 meses de idade (Grupo I), é também relatada por outros autores ${ }^{30,36}$ em crianças com meningite purulenta de várias etiologias.

1.4 Vômitos - Essa anormalidade clínica foi registrada em 195 pacientes $(76,47 \%)$. Outros autores ${ }^{11,24,27}$ referem incidêrcia próxima a essa, em pacientes com meningite meningocócica. A presença de vômitos foi anotada em $61,22 \%$ dos pacientes do Grupo I, em $79,49 \%$ do Grupo II, em $\mathbf{8 2 , 2 6 \%}$ do Grupo III e em 78,79\% do Grupo IV.

1.5 Fontanela Tensa ou Abaulada - Esse sinal foi constatado em 31 $(63,26 \%)$ de nossos pacientes do Grupo I. Convém ser lembrado que a avaliação desse sinal pode ser falseado por diversos motivos tais como desidratação e emprego de certos medicamentos.

1.6 Cefaléia - Esse sintoma foi observado em 53,04\% de nossos 181 pacientes maiores de dois anos de idade. Em relação aos grupos estudados, observamos que a incidência desse sintoma foi de $35,85 \%$ no Grupo II, de $53,22 \%$ no Grupo III e de $66,67 \%$ no Grupo IV. Dispensa lembrar que a pesquisa da cefaléia é geralmente prejudicada, já pela baixa idade dos pacientés, já pela incapacidade de colaboração na fase inicial.

1.7 Petéquias - Esse sinal foi detectado em $36,47 \%$ de nossos pacientes. A freqüência com que as alterações cutâneas, em pacientes com meningite meningocócica, são descritas por diversos autores 16,22,24,27,49 é bastante variável.

1.8 Dores Musculares - Esse sintoma foi constatado em 6,08\% de nossos 181 pacientes maiores de dois anos de idade. A exemplo do que foi dito com referência à cefaléia, aqui também prescinde lembrar que a pesquisa desse sintoma é geralmente prejudicada, pela incapacidade de colaboração na fase inicial.

1.9 Acometimento do IIIo Nervo Craniano - Constatamos disfunção desse nervo craniano em três pacientes. A medida que o estado de consciência melhorou, houve regressão dos sinais de disfunção desse nervo. Provavelmente, em nossos pacientes, esses sinais eram decorrentes de hipertensão intracraniana. Todos evoluiram bem, recebendo alta assintomáticos.

2. Intercorrências Neurológicas Após a Admissão Hospitalar - Após a admissão hospitalar constatamos anormalidades neurológicas em 27 pacientes $(10,59 \%)$ dessa casuística.

2.1 Manifestaçóes Epilépticas (ME) - Em nossas casuística, as ME surgiram antes da admissão hospitalar em 27 pacientes (10,59\%), e foram regis- 
tradas após a internação em $16(6,27 \%)$. Verificamos que as $M E$ ocorreram nas formas generalizada, focal e mista. Nenhum de nossos pacientes apresentou estado de mal epiléptico. Considerando, conjuntamente, os períodos pré e pós admissão hospitalar, constatamos que as crises epilépticas ocorreram em 38 pacientes $(14,90 \%)$. Desses 38 pacientes, em 28, essas crises ocorreram apenas uma vez e, em 10, foram repetitivas. Observamos, ainda, que essas crises ocorreram, inicialmente, antes e nos três primeiros dias da hospitalização. $\mathrm{Da}$ análise dos pacientes, que apresentaram $\mathrm{ME}$, verificamos que $25(65,79 \%)$ evoluiram sem anormalidades, $5(13,16 \%)$ evoluiram para o óbito e $8(21,05 \%)$ apresentavam outras anormalidades neurológicas, sendo que desses, três estavam assintomáticos por ocasião da alta hospitalar. Contrariamente à opinião de alguns autores ${ }^{30,32}$, entendemos não ser a $M E$ por si só responsável pela determinação do pior prognóstico para os pacientes com meningite mas, sim, que este sintoma bem como outros sinais e sintomas, nesses pacientes, espelham as agressões sofridas pelo sistema nervoso, estando o prognóstico na dependência da intensidade dessas agressões. Concordamos com os autores $10,15,21,47$ que responsabilizam as vasculites, coleções subdurais, distúrbios hidreletrolíticos e a encefalopatia tóxico-infecciosa pelas crises epilépticas, bem como por outros sinais e sintomas constatados nos pacientes com meningites basterianas agudas. Discordamos dos autores ${ }^{30,32}$ que sugerem a proteção das crianças menores com meningites bacterianas agudas mediante o uso rotineiro de medicação anticonvulsivante, já que as $M E$ geralmente ocorrem nos três primeiros dias e os anticonvulsivantes habitualmente usados, como o fenobarbital e a difenilhidantoina, atingem niveis plasmáticos satisfatórios em prazo superior a esse 8,9. Para tal proteção, teríamos que obter níveis plasmáticos úteis de modo mais rápido $\mathrm{e}$, conseqücntemente, doses bem maiores que as habituais teriam que ser empregadas, como aquelas usadas para o tratamento do estado de mal epiléptico e das crises repetitivas. Tais doses não são completamente desprovidas de efeitos colaterais, e, por sua vez, a medicação anticonvulsivante não elimina o fator ou fatores causadores das $M E$ nesses pacientes. Porém, estamos de pleno acordo com a administração de anticonvulsivantes em doses eficazes e de cuidados gerais necessários no tratamento dos pacientes com crises epilépticas. Além do tratamento medicamentoso, reputamos de fundamental importância a investigação de fator ou fatores responsáveis pelas crises nesses pacientes, pois alguns deles, como por exemplo as coleções subdurais e os distúrbios hidreletrolíticos, merecem outros cuidados que o simples uso de drogas anticonvulsivantes. Em nossos pacientes, após a admissão hospitalar, a ME foi a intercorrência neurológica mais encontrada. Estudando-se os diversos grupos etários, o acentuado destaque para essa intercorrência decorreu da sua grande incidência entre os pacientes do Grupo I.

2.2 Surdez - Após as ME, a surdez juntamente com a ataxia foram as intercorrências neurológicas mais freqüentemente registradas durante a internação. Dentre nossos pacientes, constatamos surdez em 6 casos (2,35\%). Merece ser mencionado, ainda, que é bastante comum a associação desse sintoma com a ataxia. Em quatro pacientes, a surdez era bilateral, completa e persistia por ocasião da alta; em um paciente era bilateral, parcial e persistia por ocasião da 
alta; e em outro paciente era bilateral, parcial e transitória. Dos quatro grupos etários abordados, essa anormalidade foi notada apenas nos Grupos III e IV. A associação de surdez e ataxia em pacientes com meningite bacteriana aguda é referida por diversos autores $14,11,23,28,35,42,51$. Dos nossos 6 pacientes com surdez, quatro apresentavam ataxia concomitantemente.

2.3 Ataxia - Em nossos pacientes, o quadro atáxico era predominantemente axial. Essa anormalidade foi constatada em 6 casos $(2,35 \%)$, dos quais quatro concomitantemente apresentavam surdez. A ataxia, como uma complicação da meningite meningocócica, é referida por vários autores 14,17,23,27,51 e tem bom prognóstico.

2.4 Déficits Motores (DM) - Entre nossos 255 casos, constatamos déficits motores em quatro. Desses, três pacientes apresentavam hemiparesia esquerda e um, tetraparesia. Alterações da motricidade, em pacientes com meningite meningocócica, têm sido relatadas por vários autores $3,14,17,22,27,40,46$. Nesses pacientes, os DM são pouco freqüentes e usualmente transitórios 3,14,17,46. Dos nossos quatro pacientes com DM, três haviam apresentado crises convulsivas e um deles, concomitantemente, coleção subdural. A freqüente associação de alteraçōes motoras e crises convulsivas, em pacientes com meningite, tem também sido observada por outros autores $3,14,17,30$.

2.5 Involução Neuropsicomotora (INPM) - Essa anormalidade neurológica foi registrada em três de nossos pacientes. A INPM persistia, ainda por ocasião da alta, nesses pacientes. Alteraçōes psicomotoras, em crianças, pós meningite meningocócica, também têm sido mencionadas por alguns autores 36,45.

2.6 Coleção Subdural (CS) - No estudo de nosso matcrial, verificamos CS em dois pacientes. A CS pós-meningite prevalece nos pacientes menores de um ano de idade. Segundo a maioria dos autores, ela é rara após 18 meses de idade. Conforme Farmer e Wise ${ }^{18}$, a maior incidência de CS nas crianças, deve-se ao fato de ser a barreira leptomeníngea menos eficiente nessa faixa etária. Os nossos dois casos de CS ocorreram entre os 49 pacientes do Grupo I. A patogênese da CS nas meningites permanece ainda obscura. A hipótese patogênica baseada no aumento da permeabilidade dos vasos é a mais aceita. A infecção no espaço subaracnóideo determinaria alterações nas paredes finas dos capilares e vasos da camada interna da dura-máter, com excessiva passagem de albumina e água para dentro do espaço subdural 10,15,29. Os critérios clínicos indicativos de CS mais relatados na literatura, como a persistência de febre durante o tratamento, má evolução clínica, sinais de hipertensão intracraniana, convulsões focais ou generalizadas e déficits neurológicos focais, embora sugestivos, não são absolutos. Em muitos casos a CS é assintomática e, em outras ocasiões, a CS pode estar ausente quando tal sintomatologia está presente 20. Segundo este mesmo autor 20 , a CS pode ser responsável pelo aumento da pressão intracraniana e possivelmente por sinais neurológicos focais. A melhor conduta a ser seguida, nos pacientes com CS, constitui assunto ainda polêmico. Dodge e Swartz ${ }^{15}$ mencionam que na ausência de sinais ou sintomas de hipertensão intracraniana, ausência de aumento do perímetro cefálico ou de 
aumento da área de transiluminação, as punções repetidas da CS são desnecessárias, uma vez que a CS desaparece com o passar do tempo. Quando o tecido cerebral sofre grande destruição no curso de uma meningite, a CS pode persistir indefinidamente, ocupando o espaço deixado pelo desaparecimento da substância cerebral ${ }^{37}$. A conduta por nós adotada no tratamento da CS sintomática, consiste em punção do espaço subdural, conforme descrita por Mạtson ${ }^{29}$, deixando-se gotejar através da agulha de punção até $15 \mathrm{ml}$ para cada lado. A punção poderá ser repetida, se necessário, diariamente, por um período de até duas semanas. Nos casos de persistência da CS, com evidência de hípertensão intracraniana, após essa conduta, encaminhamos para tratamento cirúrgico. Dos nossos casos, em um foram suficientes apenas duas punções e, no outro, tão somente uma.

2.7 Distúrbios da Conduta - Seqüelas psicológicas e psiquiátricas pós-meningite são bastante conhecidas. Em 1946, Pai 33 mencionava que o meningococo não somente "morde" as meninges, como também "lambe" o encéfalo, $\mathrm{e}$ que a deterioração mental, alterações da personalidade, alterações do caráter e distúrbios da conduta podem ser o resultado de alterações cerebrais orgânicas. Distúrbios da conduta foram constatados em um paciente do Grupo II e em outro do Grupo IV, neles persistindo por ocasião da alta.

3. Liquido Cefalorraqueano por Ocasião da Admissão Hospitalar - Entre os nossos pacientes, que exibiam os dados completos do exame citológico e químico do LCR, a maioria apresentava dados compativeis com meningite bacteriana aguda. Por outro lado, em alguns pacientes, o exame citológico e químico não eram sugestivos de tal moléstia. Assim sendo, é válido ressalvar que a presença de elevada pleocitose, predominância de neutrófilos, altas taxas de proteínas e baixas taxas de glicose no LCR de pacientes com meningite meningocócica costumam ser a regra mas que, como toda regra, apresenta exceções.

3.1 Células no LCR por Ocasião da Internação - O número de células variou de uma $/ \mathrm{mm}^{3}$ em um paciente, a mais de $50.000 / \mathrm{mm}^{3}$ em quatro pacientes. A presença de elevada pleocitose no LCR, na maioria dos pacientes com meningite meningocócica, é fato sobejamente conhecido. Pequeno número de células e mesmo taxas, dentro dos limites da normalidade, embora seja pouco comum, não constitui nenhum fato inédito. Diversos autores têm mencionado casos de celularidade normal $6,34,5 \cdot a$ e baixa celularidade $6,11,27,50$ em pacientes com meningite meningocócica.

3.2 Neutrófilos no LCR por Ocasiâo da Internação - A porcentagem de neutrófilos variou de zero\% em um caso, a acima de $90 \%$, em 55,45\% dos casos. A predominância de leucócitos polimorfonucleares no LCR de pacientes com meningite meningocócica, é constatação bastante divulgada. Entretanto, a não prevalência deles, em pacientes com meningites bacterianas agudas, também tem sido mencionada por outros autores $19,25,31$.

3.3 Proteinas no LCR por Ocasião da Internação - A taxa de proteínas em $\mathrm{mg} \%$ variou de inferior a 30 em $1,40 \%$ dos casos, a superior a 1.000 , em 
4,21\%. Que hiperproteinorraquia é encontrada freqüentemente, em pacientes com meningite meningocócica é afirmativa inconteste, no entanto, cabe a ressalva de que, casos com proteinorraquia normal, também têm sido constatados por outros autores 27,50 .

3.4 Glicose no LCR por Ocasião da Internação - As taxas de glicose em $\mathrm{mg} \%$ variaram de inferior a $10 \mathrm{em} 72,06 \%$ dos casos, a igual ou superior a $50 \mathrm{em} \mathrm{8,34 \% .} \mathrm{Nossos} \mathrm{dados} \mathrm{confirmam} \mathrm{que} \mathrm{hipoglicorraquia} \mathrm{ocorre} \mathrm{na} \mathrm{maioria}$ dos pacientes com meningite meningocócica, mas, confirmam também a existência de casos com glicorraguia normal, referida por outros autores 24,50 .

Os dados expostos permitem-nos afirmar que o exame do LCR deve ser o mais completo possivel, a fim de que aqueles pacientes, com exame citológico e químico pouco sugestivos de meningite bacteriana aguda, não sejam prejudicados.

4. Mortalidade - Entre os 255 pacientes de nossa casuística, registramos 11 casos $(4,31 \%)$ de óbito. Em 9 pacientes, o óbito ocorreu nas primeiras 24 horas após a hospitalização. Nos quatro grupos etários estudados, observamos que essa fatalidade ocorreu em um paciente $(2,04 \%)$ do Grupo I, em quatro $(5,12 \%)$ do Grupo II, em $5(8,06 \%)$ do Grupo III e em um $(1,52 \%)$ do Grupo IV. Taxa de mortalidade próxima à nossa, tem sido mencionada por alguns autores ${ }^{27,36,43}$ que também estudaram crianças com meningite meningocócica, em época vizinha àquela de nossos casos. Maior incidência de óbitos, nos periodos iniciais dessa moléstia, tem sido também relatada por outros autores ${ }^{12,22,24,43 .}$.

5. Anormalidades Neurológicas por Ocasião da Alta Hospitalar - Entre nossos pacientes deparamos com anormalidades neurológicas em 14 (5,49\%). Nos diversos grupos etários estudados observamos anormalidades neurológicas em $8,16 \%$ dos pacientes do Grupo I, em $5,13 \%$ do Grupo II, em 4,84\% do Grupo III e em $4,55 \%$ do Grupo IV. Surdez e ataxia foram as anormalidades neurológicas mais comumente verificadas, entre nossos pacientes, por ocasião da alta hospitalar. Após o advento da quimioterapia e da antibioticoterapia, a surdez vem sendo a seqüela mais destacada por vários autores $3,5,17,122,51$. Além da surdez e ataxia observadas em cinco pacientes $(1,96 \%)$, constatamos, ainda, involução neuropsicomotora em três $(1,18 \%)$, déficit motor em dois $(0,78 \%)$, e distúrbios da conduta também em dois $(0,78 \%)$.

6. Liquido Cefalorraqueano na Alta Hospitalar - Os dados citológicos e químicos de 151 de nossos pacientes, após 10 a 14 dias de terapia antimicrobiana, revelaram que apenas 10 apresentavam exame dentro dos limites da normalidade, estabelecido para crianças, em nosso meio, por Spina-França ${ }^{48}$. Podemos ainda constatar que nenhum dos critérios, estabelecidos por vários outros autores $21,24,47,52,53,54$, eram preenchidos na integra por todos os pacientes desta casuística. Nenhum dos casos, por mais alterados que fossem os dados citológicos e químicos, por ocasião da interrupção da medicação anti- 
microbiana, apresentaram recrudescência da infecção meningocócica. $\mathrm{O}$ número de células $/ \mathrm{mm}^{3}$ era de até 30 em aproximadamente $2 / 3$ dos casos, e que no outro $1 / 3$ com mais de 30 , havia 7 casos em que o número de células variou de 116 a $153 / \mathrm{mm}^{3}$. As porcentagens de neutrófilos foram de até $5 \% \mathrm{em}$ aproximadamente $4 / 5$ dos casos, e que, no $1 / 5$ com mais de $5 \%$, havia um caso com 57\% de neutrófilos. As taxas de proteínas em $\mathrm{mg} \%$ foram de até 50 em aproximadamente $2 / 3$ dos casos, e que no $1 / 3$ com taxa superior a 50 , havia 7 casos com taxas entre 106 a $150 \mathrm{mg} \%$. A taxa de glicose em $\mathrm{mg} \%$ foi igual ou superior a $50 \mathrm{em}$ aproximadamente $2 / 3$ dos casos, e que no $1 / 3$ com taxa igual ou inferior a 50, havia três casos com taxas entre 25 a $20 \mathrm{mg} \%$. Com base na análise de nossos dados, e tendo em vista a inexistência, até o presente momento, de meningococo resistente aos antibióticos habitualmente usados, podemos concluir, com segurança, que exames repetidos do LCR são desnecessários para os pacientes com meningite meningocócica.

\section{CONCLUSOERS}

Do estudo clínico e do exame do líquido cefalorraqueano, em 255 crianças de zero a 12 anos de idade, com meningite por meningococo do sorogrupo $A$, podemos chegar às seguintes conclusões.

Nos pacientes menores de 13 meses de idade, a sintomatologia predominante, por ocasião da admissão hospitalar, foi o binômio alteração do estado de consciência e febre, enquanto que, nas crianças maiores predominou a tríade alteração do estado de consciência, febre e sinais de irritação meníngea. As manifestações epilépticas ocorrem principalmente antes da internação e nas primeiras 48 horas após, e são mais freqüentes nos pacientes menores de 13 meses de idade.

Intercorrências neurológicas, após a admissão hospitalar, foram constatadas em 27 pacientes $(10,59 \%)$, cabendo notar que a manifestação epiléptica foi a intercorrência mais comum, seguida, por ordem decrescente de frequiência, de ataxia e surdez, déficit motor, involução neuropsicomotora, coleção subdural e distúrbios da conduta. Óbito foi registrado em 11 pacientes (4,31\%), sendo certo que a grande maioria $(81,82 \%)$ faleceu nas primeiras 24 horas da internação.

Por ocasião da alta hospitalar, 14 pacientes (5,49\%) apresentavam anormalidades neurológicas, dentre as mais freqüentes, surdez e ataxia, com exceção dos pacientes menores de 13 meses, nos quais predominou a involução nellropsicomotora.

O LCR, além da análise rotineira citológica e química, deverá ser submetido à bacterioscopia, cultura e imunoeletroforese cruzada, para que casos pouco sugestivos de meningite bacteriana aguda não sejam prejudicados. Em pacientes com meningite meningocócica, não há necessidade de exame do LCR, para que a antibioticoterapia seja interrompida. 
Este trabalho aborda o estudo clínico e a análise do $\mathrm{LCR}$, em 255 crianças de zero a 12 anos de idade, com meningite por meningococo do sorogrupo A. Por ocasião da admissão hospitalar verificamos que 27 pacientes $(10,59 \%)$ apresentavam intercorrências neurológicas, sendo que a intercorrência mais freqüente foi a manifestação epiléptica, com predomínio nos pacientes menores de 13 meses de idade. $O$ óbito foi registrado em 11 pacientes $(4,31 \%)$. No momento da alta hospitalar, 14 pacientes $(5,49 \%)$ apresentavam anormalidades neurológicas, com prevalência para a surdez e a ataxia, com exceção dos pacientes menores de 13 meses de idade, nos quais predominou a involução neuropsicomotora. Em pacientes com meningite meningocócica, não há necessidade de exame do LCR, para que a antibioticoterapia seja interrompida.

\section{SUMMARY}

Neurologic and CSF evaluation in children with serogroup $A$ meningococcal meningitis.

Our aim is to present the results obtained from the evaluation of the neurological examination as well as chemical and cytologic data from the CSF obtained at the admission and discharge of 255 children aged between zero and 12 years with a diagnosis of serogroup A meningococcal meningitis made at the Hospital Emilio Ribas in São Paulo, Brasil, in the years of 1976 and 1977. By the time of their admission, 27 patients $(10,59 \%)$ showed positive neurologic findings besides meningeal signs. Seizures were the most common ones, with higher incidence in children under 13 months; ataxia, deafness, motor deficits, neuro-psychmotor involution, subdural effusions and disturbed behavior followed in that order. Subdural effusions were found only in those under 13 months. A fatal outcome was registered in eleven $(4,31 \%)$ patients, of which nine died in the first 24 hours after admission. By the time of hospital discharge 14 patients $(5,49 \%)$ had neurological abnormalities, deafness and ataxia being the most common ones, in the older patients. Under 13 months, developmental involution predominated. There is no need of CSF evaluation for antibiotic therapy interruption in patients with meningococcal meningitis.

\section{RFFERENCIAS}

1. ALEXANDER, W. S. - Influence of chemotherapy in the pathology of purulent leptomeningitis. Arch. Neurol. Psychiat. 63:73, 1949.

2. BANKS, H. S. - Meningococcosis. Lancet 2:635, 1948.

3. BANKS, H. S. - Meningococcosis. Lancet 2:677, 1948.

4. BANKR, H. S. \& MCCARTNEY, J. E. - Meningococcal encephalitis. Lancet 1:219, 1942.

5. BEENSON, P. B. \& WESTERMAN, E. - Cerebrospinal fever. Analysis of 3,575 case reports with special reference to sulphonamide therapy. Brit. med. J. 1:497, 1943.

6. BELL, W. F. \& MCCORMICK, W. F. - Neurologic Infection in Children. W. B. Saunders C., Philadelphia, 1975, cap 4.

7. BUCHAN, G. C. \& ALVORD, E. C. Jr. - Diffuse necrosis of subcortical white matter associated with bacterial meningitis. Neurology (Minneapolis) 19:1, 1969. 
8. BUCHTHAL, F. \& LFNNOX-BUCHTHAL; M. A. - Diphenylhydantoin: relation of anticonvulsant effect to concentration in serum. In WOODBURY, D. M.; PENRY, J. K. \& SCHMIDT, R. P. (eds.): Antieplletic Drugs. Raven Press, New York, 1972, pg. 193.

9. BUCHTHAL, F. \& LENNOX-BUCHTHAL, M. A. - Phenobarbital: relation of serum concentration to control of seizure. In WOODBURY, D. M.; PENRY, J. K. \& SCHMIDT, R. P. (eds.): Antieplleptic Drugs. Raven Press, New York, 1972, pg. 335.

10. BUTLER, I. J. \& JOHNSON, R. T. - Central nervous system infections. Pediat. Clin. N. Am. 21:649, 1974.

11. CARPENTER, R. R. \& PETERSDORF, R. G. - The clinical spectrum of bacterial meningitis. Amer. J. Med. 33:262, 1962.

12. DESMIT, E. M. - A Follow-up stidy of 110 patients treated for purulent meningitis. Arch. Dis. Child. 30:415, 1955.

13. DIAMENT, A.J. - Evolução neurológica do lactente normal. EDART, São Paulo, 1975.

14. DODGE, P. R. \& SWARTZ, M. N. - Bacterial meningitis: a review of selected aspects. II. Special neurologic problems, postmeningitic complications and clinicopathological correlation. New Engl. J. Med. 272:954, 1965.

15. DODGE, P. R. \& SWARTZ, M. N. - Bacterial meningitis: a review of selected aspects. New Engl. J. Med. 272:1003, 1965.

16. EINHORN, A. H. - Bacterial meningitis. In BARNETT, H. L. (ed.): Pediatric (15a ed.). Meredith Corps., New York, 1972, pg. 598.

17. FARMHR, T. W. - Neurologic complications during meningococcic meningitis treated with sulfonamide drugs. Arch. int. Med. 76:201, 1945.

18. FARMER, T. W. \& WISE, G. R. - Subdural empyema in infants, children and adults. Neurology (Minneapolis) 23:254, 1973.

19. FEIGIN, R. D. \& DODGE, P. R. - Bacterial meningitis: new concepts of pathophysiology and neurologic sequelae. Ped. Clin. N. Am. 23:541, 1976.

20. GOODMAN, J. M. \& MEALEY, J. Jr. - Postmeningitic subdural effusions. The syndrome and its management. J. Neurosurg. 30:658, 1969.

21. HOSFIELD, W. B. - Management and complications of acute bacterial meningitis. Postgrad. Med. 50:100, 1971.

22. HOYNE, A. L. \& BROWN, R. H. -727 meningococcic cases: Ann. int. Med. 28;241, 1948.

23. JONSSON, M. \& ALVIN, A. - A 12 year review of acute bacterial meningitis in Stockholm. Scand. J. infect. Dis. 3:141, 1971.

24. KAUFMAN, B.; LEVY, H.; ZALFZNAK, B. D. \& LITVAK, A. M. - Statistical analysis of 242 cases of meningococcus meningitis. J. Pediat. 38:705, 1951.

25. KRUGMAN, S.; WARD, R. \& KATZ, S. L. - Acute bacterial meningitis. Infectious Diseases of Children (6a ed.). C. V. Mosby Co. Saint Louis, 1977, cap. 13.

26. LEFtrVRE, A. B. - Exame neurológico da criança. In TOLOSA, A. P. M. \& CANelias, H. M. (eds.): Propedéutica Neurológica (2a ed.). Procienx, sø̃o Paulo, 1971, cap. 25.

27. LEFtVRE, A. B.; ALMEIDA, I. J. M.; SANTOS, I.; Elkis, L. C.; PAZiNato, M. Jr.; PAREDES, M. A. N.; PINTO, M. C. B.; VALENTE, M. I.; GUIMARAES, M. L. O.; GROSSMAN, R. M.; DEL PORTO, R.; GAZAL, S.; CYPEL, S. \& GOES, S. L. - Estudo clínico de 78 casos de meningite em crianças. Neuroped. latinoamer. 11:217, 1977.

28. LIEBMAN, E. P.; RONIS, M. L.; LOVRINIC, J. H. \& KATINSKY, S. E. Hearing improvement following meningitis deafness. Arch. Otolaryng. 90:470, 1969.

29. MATSON, D. D. - Neurosurgery of Infancy and Childhood (2a ed.). Charles C. Thomas Publ., Springfiels. Illinois, 1969, cap. 45.

30. MOURA-RIBEIRO, M. V. L. - Meningencefalites purulentas em crianças no primeiro ano de vida: evolução clínica e eletrencefalográfica. Tese de Livre Docencia. Faculdade de Medicina de Ribeirão Preto, Universidade de são Paulo, Brasil, 1978.

31. MURRAY, J. D.; FLEMING, P.; WEBER, J.; HSUEN, J.; BANNATYNE, R. \& ANGLIN, C. - The continuing problem of purulent meningitis in infants and children. Pediat. Clin. N. Am. 21:967, 1974. 
32. DUNSTED, C. - Significance of convulsions in children with purulent meningitis. Lancet 1:1245, 1951.

33. PAI, M. N. - Personality defects and psychiatric symptons after cerebrospinal fever in childhood - meningococcal encephalopaty. J. ment. Sc. 92:369, 1946.

34. PLUM, F. \& POSNER, J. P. - Diagnosis of Stupor and Coma. (2a ed.). F. A. Davis Co., Philadelphia, 1975, pg. 204.

35. POLLARD, R. B. - Early bilateral eighth nerve involvement in meningococcal meningitis. South. med. J. 69:343, 1976.

36. PORTILLO, J. M.; SANTOS, F.; BANCUICERAS, R. L.; FERRARI, M. A.; RIOS, E.; BAZZINO, I. R.; QUIAN, J.; FREITAS, T.; GARRIDO, M.; PELUFFO, L.; CACERES, M. P.; LOY, A. A.; FOLLE, A. U.; TARLOWSKY, M.; MENDONZA, M. P. \& THEVENET, M. C. - Meningitis supuradas. Neuroped. latinoamer. 11:181, 1977.

37. RABE, E. F.; FLYNN, R. E. \& DODGE, P. R. - Study of subdural effusions in infants with particular to the mechanism of their persistence. Neurology (Minneapolis) 12:79, 1962.

38. RAIMONDI, A. J. \& DIROCCO, C. - The physiopathogenetic basis for angiographic diagnosis of bacterial infections of the brain and its covering in children. I. Leptomeningitis. Child's Brain 5:1, 1979.

39. RORKE, L. B. \& PITTS, F. W. - Meningitis purulent: pathologic basis of clinical manifestations. Clin. Pediat. 2:64, 1963.

40. ROSS, A. T. - Meningococcic meningitis: incidence of residua following serum, sulfonamide and sulfonamide-penicillin therapy. Arch. Neurol. Psychiat. 67:89, 1952.

41. SAHS, A. L. \& JOYNT, R. J. - Meningitis. In BAKER A. B. \& BAKER L. H. (eds.). Clinical Neurology (2a ed.). Harper \& Row Publ., 1974, vol. 2, cap. 15.

42. SCHWARTZ, J. F. - Ataxia in bacterial meningitis. Neurology (Minneapolis) 22:1071, 1972.

43. SEIBEL, R. G. - Meningitis meningocócica. In PUG T.F. (coord.): Meningitis en la Infancia. Ed. Médica Panamericana, Buenos Aires, 1976, pg. 155.

44. SESHIA, S. S.; SeSHIA, M. M. K. \& SCHDEVA, R. K. - Coma in childhood. Develop. Med. Child. Neurol. 19:614, 1977.

45. SIlllaNPAA. M.; PELTONEN, T. \& NURMIKKo, T. - Social and medical prognosis of child with acute nontuberculous purulent meningitis. Acta paediat. scand., suppl. 265, 1977.

46. SLESINGER, H. A. - Complications and sequelae of meningococcic meningitis during infancy and childhood. Pennsylvania med. J., pg. 327, 1933.

47. SMITH, D. H.; INGRAM, D. L.; SMITH, A. L.; GILLES, F. \& BRESNAN, M. J. - Bacterial meningitis. Pediatrics 52:586, 1973.

48. SPINA-FRANCA, A. - Liquido cefalorraqueano na infancia. In: MARCONDES, $\mathbf{E}$. (coord.): Pediatria Básica. Sarvier, São Paulo, 1975, vol. 1, pg. 287.

49. SWARTZ, M. N. \& DODGE, P. R. - Bacterial meningitis. A review of selected aspects. New Engl. J. Med. 272:725, 1965.

50. SWARTZ, M. N. \& DODGE, P. R. - Bacterial meningitis. A review of selected aspects. New Engl. J. Med. 272:779, 1965.

51. TENG, Y. C.; LIU, J. H. \& HSU, Y. H. - Meningitis and deafness: report of 337 cases of deafness due to cerebrospinal meningitis. Chinese med. J. 81:127, 1962.

52. UNDERMAN, A. E.; OVERTURF, G. D. \& LEEDOM, J. M. - Bacterial meningitis. Disease-a-Month. Year Book Medical Publ., Chicago, vol. XXIV, february 1978.

53. WEHRLE, P. F.; MATHIES, A. W. \& LEEDOM, J. M. - The critically ill child: management of acute bacterial meningitis. Pediatrics 44:991, 1969.

54. WEHRLE, P. F.; MATHIES, A. W. \& LEFDOM, J. M. - Acute bacterial meningitis. In CLEMENT, A. S. (ed.): The Critically Ill Child. W. B. Saunders Co., Philadelphia, 1977, pg. 91.

55. ZIMMERMAN, R. A.: PATEL, S. \& BILANIUK, L. - Demonstration of purulent bacterial intracranial infections by computed tomography. Am. J. Roentgenol. 127:155, 1975.

Hospital Emilio Ribas - Av. Dr. Arnaldo - são Panlo, SP - Brasil. 